\title{
Camel-related pancreatico-duodenal injuries: a report of three cases and review of literature
}

\author{
*Abu-Zidan FM ${ }^{1,2}$, Hefny AF ${ }^{1}$, Mousa $\mathrm{H}^{2}$, Torab FC ${ }^{1}$, Hassan I ${ }^{2}$
}

1. Trauma Group, Faculty of Medicine and Health Sciences, UAE University, UAE

2. Department of Surgery, Al-Ain Hospital, Al-Ain, UAE

\begin{abstract}
Background: Human pancreatico-duodenal injuries caused by camels are extremely rare.

Objective: We report three patients who sustained camel-related pancreatico-duodenal injuries and review the literature on this topic.

Results: A 32-year camel caregiver was kicked by a camel which then stepped on his abdomen trying to kill him. The patient's abdomen was soft and lax. CT scan of the abdomen showed free retroperitoneal air. Laparotomy revealed a complete tear of the anterior wall of the second part of duodenum which was primarily repaired. A 40-year camel caregiver was directly kicked into his abdomen by a camel. He developed traumatic pancreatitis which was treated conservatively. A 31-year-old male fell down on his abdomen while riding a camel. Abdominal examination revealed tenderness and guarding. Abdominal CT Scan showed complete transection of the neck of the pancreas which was confirmed by laparotomy. The patient had distal pancreatectomy with preservation of the spleen. All patients were discharged home in good condition.

Conclusion: These cases demonstrate the misleading presentation of the camel-realted pancreatico-duodenal injuries and their unique mechanism of injury.
\end{abstract}

Key words: Duodenum, pancreas, pancreatitis, injury, trauma, camel

African Health Sciences 2013; 13(3): 762 - 767 http://dx.doi.org/10.4314/ahs.v13i3.35

\section{Introduction}

Pancreatico-duodenal injuries are uncommon. Annually, we treat about two patients with pancreatic trauma for almost 1000 trauma patients $(0.2 \%)$ admitted in our hospital ${ }^{1}$. Majority are caused by blunt trauma, mainly road traffic collisions ${ }^{1,2}$. Pancreatico-duodenal injuries may initially be missed especially when the clinical findings are not clear and the diagnosis is not suspected. Delayed diagnosis is associated with increased morbidity and mortality ${ }^{3}$. The sensitivity and specificity of hyperamylasemia for detecting pancreatic injury are low ${ }^{4,5}$. Initial serum amylase levels may be normal in $25 \%$ of patients ${ }^{3}$. Abdominal CT scan with intravenous contrast is very useful in diagnosing abdominal injuries. Nevertheless, it may miss pancreatic injuries ${ }^{6-8}$. It is advised to perform thin slice CT images and to repeat it within 24 hours if the initial exam was normal and a pancreatic injury is still clinically suspected ${ }^{9,10}$.

Pancreatic duodenal injuries are caused by crushing the duodenum and pancreas against the
*Corresponding author:
Professor Fikri Abu-Zidan
Department of Surgery
Faculty of Medicine and Health Sciences
P O Box 17666, Al-Ain
United Arab Emirates
Fax : (+971 3) 7672067
E-mail: fabuzidan@uaeu.ac.ae

vertebral column or rupture of a closed bowel loop 2, 11. Pancreatic injuries are graded to five grades ranging from minor contusion to massive disruption of the pancreatic head. Similarly, duodenal injuries are graded to five grades ranging from wall hematoma to massive disruption of the duodenopancreatic complex ${ }^{12}$. Management of these injuries may turn out to be very challenging especially when diagnosis is delayed and surgery is indicated.

Human pancreatico-duodenal injuries caused by camels are extremely rare. There are more than 15 million one hump camels worldwide, in close contact with humans, which are used for transportation, farming and as a food resource ${ }^{13,14}$. Camels can cause human injuries directly by kicks or bites or indirectly by falling while riding them ${ }^{15,16}$. Hereby we report three patients who sustained camel-related pancreatico-duodenal injuries with emphasis on their mechanism and review the literature on this topic.

\section{Case reports \\ Case 1}

A 32-year old camel caregiver was kicked by the front camel knee. The patient fell down and the camel stepped on his abdomen trying to kill him. The patient presented to our hospital complaining of mild abdominal pain. On physical examination, the patient 
was haemodynamically stable. Contusion marks were seen over the right lumber area. The abdomen was soft and lax with generalized tenderness (figure 1). Blood investigations revealed haemoglobin of 16.6 $\mathrm{g} / \mathrm{dL}$ (normal range 13-17.5 g/dL), white blood cell count of $12.1 \times 10^{9} / \mathrm{L}$ (normal range 3.9-11.2 x $10^{9} / \mathrm{L}$ ), serum bilirubin of $0.7 \mathrm{mg} / \mathrm{dL}$ (normal range $0.2-1 \mathrm{mg} / \mathrm{dL}$ ), and a serum amylase of $139 \mathrm{IU} / \mathrm{L}$ (normal range 28-100 IU/L), A CT scan of the abdomen has shown free retroperitoneal air around the right kidney (figure 2) and free intraperitoneal fluid. The liver, spleen, and kidneys were normal. Midline laparotomy was performed. A moderate amount of clear fluid and a right retroperitoneal swelling with greenish discoloration was seen. The right colon and duodenum were mobilized medially using the Cattel Braasch and Kocher maneuvers which allowed excellent visualization of the entire duodenum. There was a complete tear of the anterior wall of the second part of duodenum, less than half of its diameter, with greenish discoloration (bile staining) and crepitus in the surrounding tissues (figure 3). The gastrocolic omentum was divided and the retroperitoneum was entered. The pancreas was properly examined and it was normal. The devitalized edges of the anterior wall of the duodenum were refreshed and repaired in two layers using absorbable sutures (No 3/0 PDS). Peritoneal toilet with 4 liters warm normal saline was performed. Two closed drains were left, a retroperitoneal drain near the repaired duodenum and a pelvic drain. A nasojejunal tube was inserted. Rocephin (ceftriaxone sodium, 2 gms once daily) and metronidazole (500 mg 8 hourly) were given intravenously for 7 days. The postoperative period was uneventful and the patient was discharged home on day 16 in good general condition.

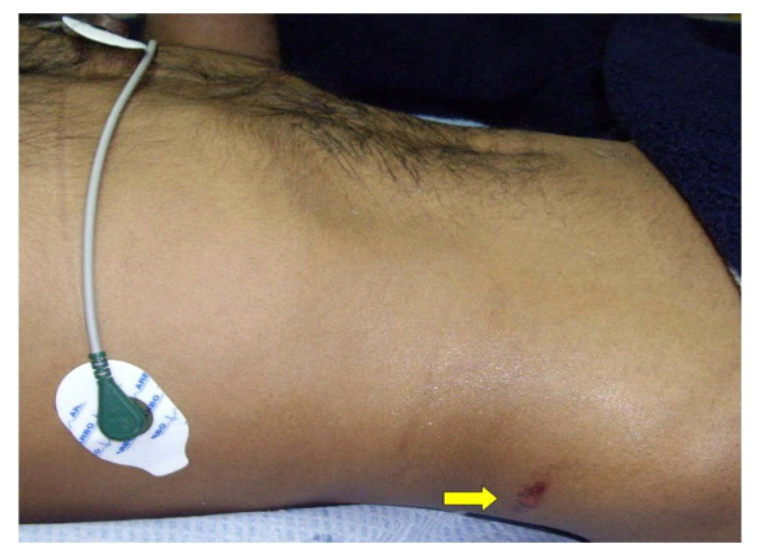

Figure 1: A 32-year-old male who was stepped on by a camel on his abdomen. Contusion marks are seen on the right lumber region (arrow). The abdomen was scaphoid, soft and lax but with generalized tenderness.

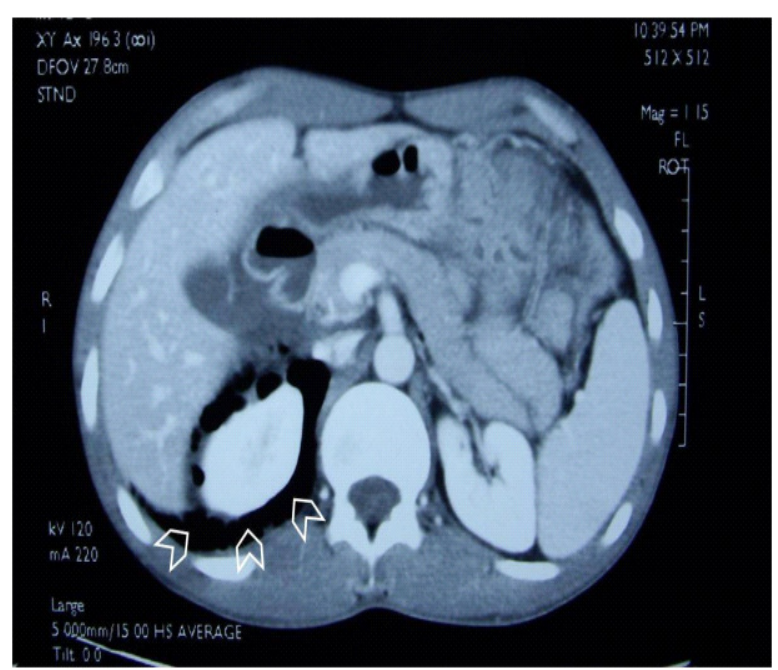

Figure 2: Abdominal CT scan with intravenous contrast showing free retroperitoneal air around the right kidney (arrow heads)

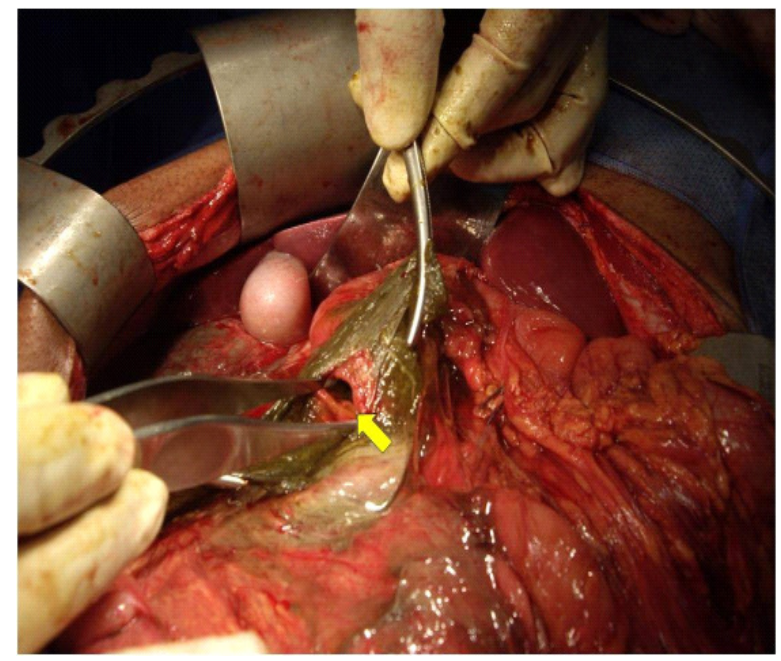

Figure 3: Laparotomy showing a complete tear of the anterior wall of the second part of duodenum, less than half of its diameter (arrow).

\section{Case 2}

A 40-year old camel caregiver was kicked by camel front knee during a camel race. He was holding the camel rope to release it but the camel kicked his abdomen. The patient presented to the hospital 24 hours after trauma complaining of abdominal pain. On examination, the patient was haemodynamically stable with tenderness in the epigastrium. The abdomen was soft and lax. Blood investigations revealed haemoglobin of $13.6 \mathrm{~g} / \mathrm{dL}$ (normal range 13-17.5 g/dL), white blood cell count of $18.1 \mathrm{x}$ $10^{9} / \mathrm{L}$ (normal range 3.9-11.2 $\times 10^{9} / \mathrm{L}$ ), CRP of 1.62 (normal range below 7.5), serum bilirubin of 1.69 $\mathrm{mg} / \mathrm{dL}$ (normal range $0.2-1 \mathrm{mg} / \mathrm{dL}$ ), blood urea nitrogen of $19 \mathrm{mg} / \mathrm{dL}$ (normal range $5-25 \mathrm{mg}$ / 
$\mathrm{dL}$ ), haematocrit of $40.2 \%$ (normal range 38.7$52.2 \%$ ), blood glucose of $141 \mathrm{mg} / \mathrm{dL}$ (normal range $70-100 \mathrm{mg} / \mathrm{dL}$ ), and serum amylase of $2500 \mathrm{IU} /$ $\mathrm{L}$ (normal range 28-100 IU/L). Abdominal CT scan was normal. The patient was admitted to the hospital, managed conservatively, and kept under observation for three days. The abdominal pain subsided and the repeated serum amylase level was normal. The patient was discharged home with no complications.

\section{Case 3}

A 31-year-old male presented to the Emergency Department, after falling down on his abdomen while riding a camel. He complained of epigastric pain radiating to the back associated with nausea and vomiting. Abdominal examination revealed tenderness in the upper abdomen. His blood pressure was $110 / 80 \mathrm{mmHg}$, his pulse was 69 beat per minute, and his temperature was $37^{\circ} \mathrm{C}$. Abdominal CT scan revealed a hepatic subcapsular haematoma near the porta hepatis in segment IV. Blood investigations showed a haemoglobin of 16.5 (normal range 13-17.5 g/dL), white blood cell count of $22.1 \times 10^{9} / \mathrm{L}$ (normal range 3.9-11.2 × 10\% $/ \mathrm{L}$ ), CRP of 1.86 (normal range below 7.5), and amylase level of 323 units (normal range 28-100 IU/L). The patient was admitted to the surgical ward for observation and treated with intravenous fluids and analgesia. 24 hours later, the abdominal findings worsened with rebound tenderness and guarding. His serum amylase raised to $1366 \mathrm{IU} / \mathrm{L}$ while serum lipase level was 400 (Normal high $=51)$. The initial abdominal CT scan was reviewed and a coronal reconstruction was done which showed transection at the neck of the pancreas which was missed (figure 4A). An MRI of the abdomen has confirmed the findings. Midline laparotomy was performed. The gastrocolic omentum was divided and the retroperitoneum was entered. The duodenum was mobilized using Kocher maneuver. There was a complete transection of the neck of the pancreas (figure 4B), a hepatic sub capsular hematoma and a serosal tear in the pyloric region. The patient had distal pancreatectomy with preservation of the spleen. Distal pancreatectomy was performed without mobilising the spleen so as to prevent postoperative spelnic torsion. The distal pancreas was dissected from the transected end towards the tail. Branches of the splenic vein and artery were divided between metallic clips. The proximal pancreatic duct was identified and closed with PDS 4/0 (figure 5). A haemostatic absorbable tissue (Surgicel; Ethicon
Inc., USA) was placed over the pancreatic stump and the stump was closed with a running PDS suture (4/0) through the Surgicel (figure 6). The serosal tear of the pylorus was closed using 4/0 PDS continuous sutures. The subcapsular hepatic hematoma was intact and was left alone. Two closed drains were left, one at the pancreatic stump area and the other at the perisplenic area. Primary mass closure of the abdomen was performed using two loops of nylon (No 1) threads. On the $4^{\text {th }}$ postoperative day, the patient complained of sudden severe abdominal pain and sweating. His blood pressure was 110/70 and his pulse 150 beats per minute. Abdominal CT showed large amount of free fluid. Urgent reexploration of the abdomen revealed 1.5 litres of blood and a rupture of the subcapsular haematoma. There was continuous venous oozing of the raw surface of the liver at the site of ruptured haematoma. Haemostasis was achieved using a bipolar diathermy and Surgicel. The edge of the pancreatic resection and the splenic vessels were intact. The patient had an uneventful recovery and was discharged home at day 11 in good general condition.
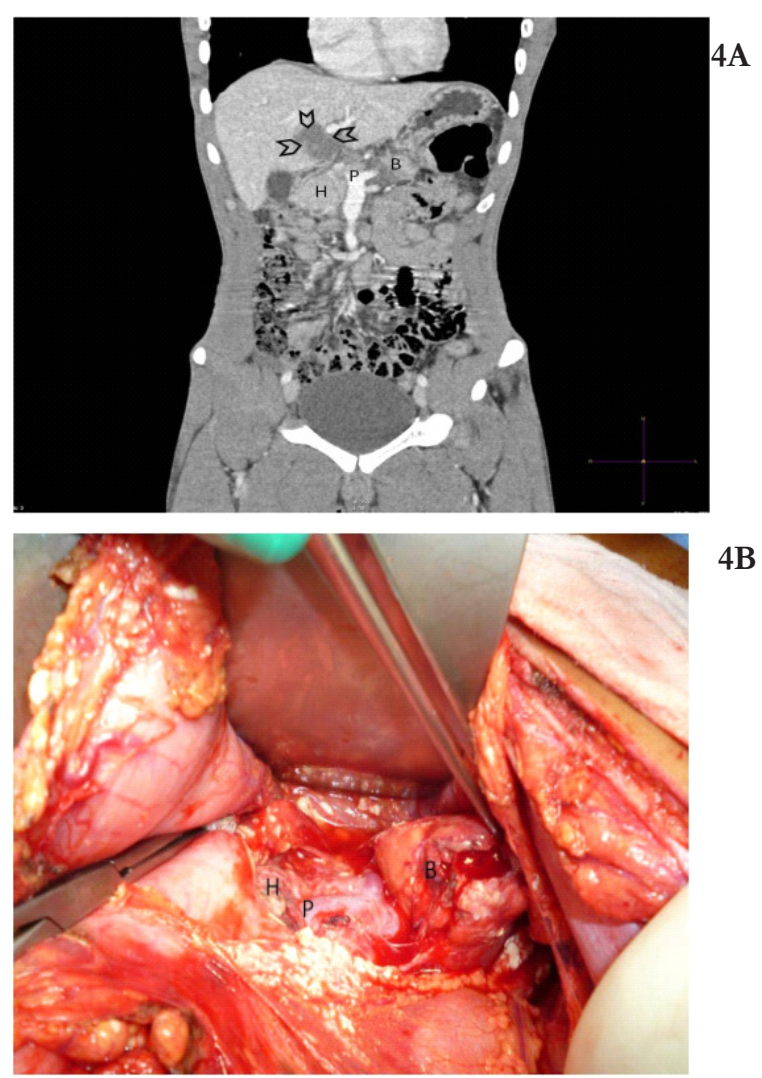

Figure 4A and 4B: Coronal reconstruction of abdominal CT Scan with intravenous contrast (Figure 4A) showing a transection at the neck of the pancreas between the head $(\mathrm{H})$ and body $(\mathrm{B})$ of the pancreas and a subcapsular haematoma of the liver in segment IV (arrow heads). $P=$ portal vein.

African Health Sciences Vol 13 Issue 3 September 2013 
These findings were confirmed by a laparotomy Figure 4B. $H=$ head of pancreas, $B=$ body of the pancreas and $\mathbf{P}=$ portal vein

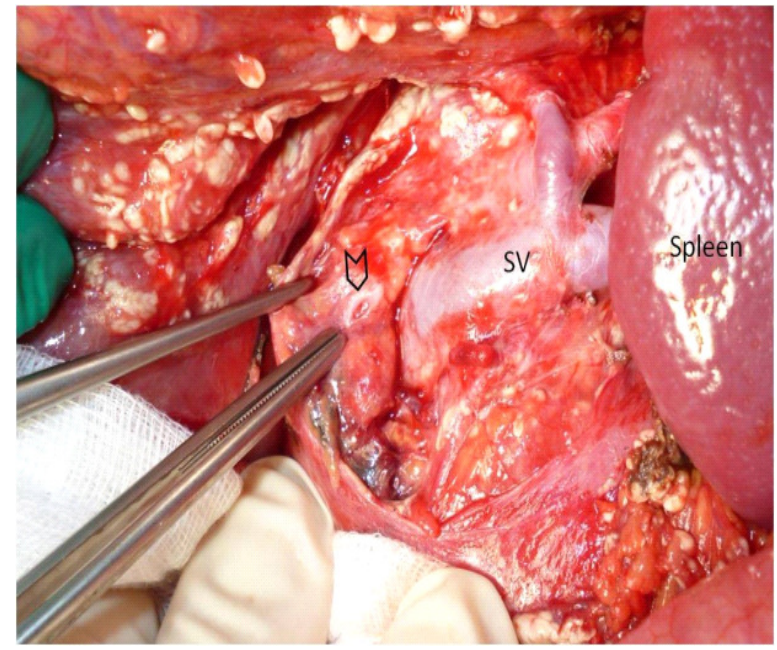

Figure 5:Distal pancreatectomy with preservation of the spleen was performed. The arrow head indicates the proximal pancreatic duct before closure. SV = splenic vein. Notice the pale yellow-white nodules of the omentum caused by fat necrosis which resemble drops of wax

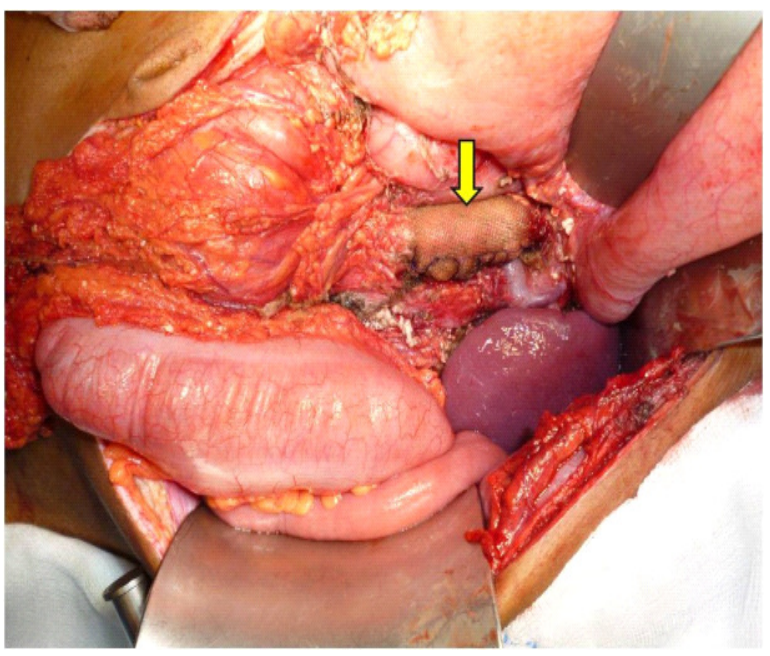

Figure 6: A haemostatic absorbable tissue (Surgicel; Ethicon Inc., USA) was placed over the pancreatic stump (arrow) and the stump was closed with a running PDS suture (4/0) through the Surgicel

\section{Discussion}

There is only one previous reported case of camelrelated pancreatico-duodenal injuries in the literature. A child, out of 78 child camel jockeys, fell from a camel and sustained laceration of the fourth part of the duodenum due to a spinal injury, into which the fourth part of the duodenum was caught and injured. This injury was repaired surgically ${ }^{17}$.

Camel kicks are the leading mechanism of camel-related injuries of humans followed by falling from a camel ${ }^{15}$. The camel may kick with the front knee or the back hoof which may reach up to the level of the head of the patient ${ }^{15}$. This explains the high percentage of the head, chest and abdominal injuries caused by camel kicks. The abdomen was injured in $20 \%$ of the patients kicked by camels ${ }^{15}$. A camel stepped on the second patient with its hoof after kicking him, while the third patient fell down while riding a camel. The severity of animal-related injuries will increase with the increased complexity of the mechanism of injury ${ }^{18}$.

Pancreatico-duodenal injuries can be easily missed ${ }^{1}$, 2. Abdominal examination of two of our patients showed only tenderness while the abdomen was soft and lax. The retroperitoneal location of the duodenum and pancreas limits the peritoneal irritation during the abdominal examination ${ }^{2}$. Our first patient had extensive retro-pneumoperitoneal air. Despite that, abdominal findings were minimum. If the duodenal perforation is properly controlled, then air will be absorbed with time. The duodenal injury of the first patient was grade II injury. It was primarily repaired, the retroperitoneal space was drained and the patient was covered with antibiotics. This prevented spread of infection in the retroperitoneal space.

We are convinced by the clinical picture that our second patient had traumatic pancreatitis despite the initial normal CT scan. The patient had a localized epigasrtic pain with very high serum amylase level of more than 20 times the normal upper limit. Pancreatitis is diagnosed clinically as abdominal pain associated with an increased serum amylase concentration exceeding three times the normal upper limit ${ }^{19,20}$. Increased serum amylase alone may occur after minor pancreatic contusions and cannot be used to determine the grade of pancreatic injury ${ }^{3}$. The early CT scan was normal in 14\% of patients who had complicated acute pancreatitis ${ }^{21}$.

There are limitations regarding the use of serum amylase to diagnose pancreatic trauma because it can be negative in early stages of less than 3 hours after the injury ${ }^{22}$. Furthermore, it may be raised without serious abdominal injuries. Nevertheless, our second patient presented after 24 hours of the injury. The most important factor that affects the serum 
amylase level on admission is the elapsed time from injury to admission ${ }^{22}$. About $70 \%$ of the patients who have pancreatic injuries will have raised serum amylase on admission ${ }^{3,23}$. This percentage will increase to about $90 \%$ when serial measurements were done ${ }^{3}$. The progressive increase of serum amylase, as occurred in the third patient, should be taken seriously and pancreatic injury should be suspected $^{3,22}$.

Non operative management of pediatric pancreatic injuries is recommended having a success rate of more than $80 \%{ }^{24}$. We have treated our second adult patient conservatively. Non operative management is not commonly used in adults. Duschesne et al have recently reported the first series of non operative management of low grade blunt pancreatic injuries in adults ${ }^{23}$. Interestingly, adult patients who had pancreatic injury grade I and II proven by CT scan had a success rate of non operative management of more than $85 \%{ }^{23}$. We did not repeat the CT scan in the second patient because the patient clinically recovered completely without any complaints or clinical findings.

Our third patient had grade III pancreatic injury. Distal pancreatectomy with or without splenectomy is the advised procedure. We did preserve the spleen because the patient was haemodynamically stable. Grade V injuries can be treated by damage control surgery, if needed, followed by definitive operation at a later stage ${ }^{25,26}$.

\section{Conclusion}

Our cases demonstrate the unique mechanism and severity of camel-related pancreatico-duodenal injuries, their misleading presentation, and difficulties encountered in their management. High clinical suspicion, strict clinical observation, and early surgical intervention when indicated are important for a favorable outcome.

\section{References}

1. Ahmad I, Branicki FJ, Ramadhan K, El-Ashaal Y, Abu-Zidan FM. Pancreatic injuries in the United Arab Emirates. Scand J Surg. 2008; 97: 243-247.

2. Abu-Nema T, Omar OF, Abu-Zidan FM, AlHilaly MA: Blunt injuries of the pancreas and duodenum in Kuwait. Saudi Med J 1994; 15: 34 38.

3. Bradley EL 3rd, Young PR Jr, Chang MC, Allen JE, Baker CC, Meredith W, Reed L, Thomason
M. Diagnosis and initial management of blunt pancreatic trauma: guidelines from a multiinstitutional review. Ann Surg. 1998; 227: 861-869.

4. Cogbill TH, Moore EE, Kashuk JL Changing trends in the management of pancreatic trauma. Arch Surg 1982; 117: 722-728.

5. Olsen WR. The serum amylase in blunt abdominal trauma. J Trauma 1973; 13: 200-204.

6. Jobst MA, Canty TG Sr, Lynch FP. Management of pancreatic injury in pediatric blunt abdominal trauma. J Pediatr Surg 1999; 34:818-835.

7. Hall RI, Lavelle MI, Venables CW. Use of ERCP to identify the site of traumatic injuries of the main pancreatic duct in children. Br J Surg 1986; 73: 411-412.

8. Rescorla FJ, Plumley DA, Sherman S, Scherer LR 3rd, West KW, Grosfeld JL. The efficacy of early ERCP in pediatric pancreatic trauma. $J$ Pediatr Surg 1995; 30: 336-340.

9. Meier DE, Coln CD, Hicks BA, Guzzetta PC. Early operation in children with pancreas transection. J Pediatr Surg 2001; 50:1001-1007.

10. Wales PW. Shuckett B, Kim PCW. Long-term outcome after non-operative management of complete traumatic pancreatic transection in children. J Pediatr Surg 2001; 36: 823-827.

11. Eid HO, Abu-Zidan FM. Biomechanics of road traffic collision injuries: a clinician's perspective. Singapore Med J. 2007; 48: 693-700.

12. Moore EE, Cogbill TH, Malangoni MA, Jurkovich GJ, Champion HR, Gennarelli TA, McAninch JW, Pachter HL, Shackford SR, Trafton PG. Organ injury scaling. II. Pancreas, duodenum, small bowl, colon, and rectum. J Trauma 1990; 30:1427-1429

13. Dorman AE. The camel in health and disease. 2. Aspects of the husbandry and management of the genus Camelus. Br Vet J 1984; 140:616-633.

14. Australian Goverment. Department of Sustainability, Environment, Water, Population and Communities. Camel fact sheet http:// www.environment.gov.au/biodiversity/invasive/ publications / camel-factsheet.html [Accessed July 24, 2012].

15. Abu-Zidan FM, Hefny AF, Eid HO, Bashir MO, Branicki FJ. Camel-Related Injuries: Prospective Study of 212 Patients. World J Surg. 2012;36:23842389.

16. Abu-Zidan FM, Eid HO, Hefny AF, Bashir MO, Branicki F. Camel bite injuries in United Arab Emirates: A 6 year prospective study. Injury 2012; 43:1617-1620. 
17. Nawaz A, Matta H, Hamchou M, Jacobsz A, Al Salem AH. Camel-related injuries in the pediatric age group. J Pediatr Surg 2005; 40:1248-1251.

18. Abu-Zidan FM, Rao S. Factors affecting the severity of horse-related injuries. Injury 2003; 34:897-900.

19. Abu-Zidan FM, Bonham MJ, Windsor JA. Severity of acute pancreatitis: a multivariate analysis of oxidative stress markers and modified Glasgow criteria. BrJ Surg. 2000; 87: 1019-1023.

20. Frossard JL, Steer ML, Pastor CM. Acute pancreatitis. Lancet 2008; 371: 143-52.

21. Fan ST, Choi TK, Chan FL, Lai EC, Wong J. Management of complicated acute pancreatitis: impact of computed tomography. J Gastroenterol Hepatol. 1990; 5: 103-109.

22. Takishima T, Sugimoto K, Hirata M, Asari Y, Ohwada T, Kakita A. Serum amylase level on admission in the diagnosis of blunt injury to the pancreas: its significance and limitations. Ann Surg. 1997; 226:70-76.

23. Duchesne JC, Schmieg R, Islam S, Olivier J, McSwain $\mathrm{N}$. Selective nonoperative management of low-grade blunt pancreatic injury: are we there yet? J Trauma. 2008; 65: 49-53.

24. Cigdem MK, Senturk S, Onen A, Siga M, Akay H, Otcu S. Nonoperative management of pancreatic injuries in pediatric patients. Surg Today. 2011; 41:655-659.

25. Rickard MJ, Brohi K, Bautz PC. Pancreatic and duodenal injuries: keep it simple. ANZ J Surg 2005; 75: 581-586.

26. Degiannis E, Glapa M, Loukogeorgakis SP, Smith MD. Management of pancreatic trauma. Injury 2008;39: 2129. 